\title{
A review on flammability of epoxy polymer, cellulosic and non-cellulosic fiber reinforced epoxy composites
}

\begin{abstract}
Natural fiber is well-known reinforcement filler in polymer-matrix composites. Composite components like organic polymers and natural fibers are natural fire conductors as the natural fiber consists of cellulose, hemicellulose, and lignin, and hence are as highly flammable as wood. Natural fiber reinforced composite materials are progressively being used in a variety of applications where their fire response is a hazardous consideration, for example, in the automotive (transportation) and building-construction industries. As a result, an awareness of their performance or response during a fire and the use of conventional fire retardants are of great importance, as they are subject to thermal decomposition when exposed to intensive high heat or fire sources. In this review paper, fire flammability is the main concern for cellulosic and non-cellulosic fiber-reinforced polymer composites, especially epoxy composites. This paper reviews the literature on the recent developments in flammability studies concerning polymers, epoxy polymers, cellulosic-fibers, and non-cellulosic fiberreinforced epoxy bio-composites. The prime objective of this review is to expand the reach of "fire retardants for polymer materials and composites" to the science community, including physicists, chemists, and engineers in order to broaden the range of their applications.
\end{abstract}

Keyword: Natural fiber; Epoxy polymer; Composite; Fire retardants; Flammability properties 
